\title{
Acute upper gastrointestinal bleeding in patients with AIDS: a relatively uncommon condition associated with reduced survival
}

\author{
F Parente, M Cernuschi, L Valsecchi, G Rizzardini, M Musicco, A Lazzarin, G Bianchi Porro
}

\begin{abstract}
To determine the cumulative incidence of acute upper gastrointestinal bleeding and its effect upon survival in patients with AIDS, 453 consecutive AIDS patients diagnosed in our hospital between June 1985 and March 1989 were followed for a median period of six months (maximum 42 months). The cumulative probability of acute gastrointestinal bleeding was $3 \%$ at six months and $6 \%$ at 14 months. This event was associated with significantly reduced survival. Independent risk factors for bleeding were: severe thrombocytopenia at the time of diagnosis and non-Hodgkin's lymphoma as the first clinical manifestation of AIDS. The potential causes of bleeding were investigated in all cases by emergency endoscopy or by necropsy examination in those patients whose clinical condition precluded the procedure. In nine of $\mathbf{1 5}$ patients, bleeding was due to lesions specifically associated with AIDS, but in the remainder the source of bleeding was not a direct consequence of HIV infection. We conclude that acute upper gastrointestinal bleeding rarely complicates the course of AIDS, but its occurrence is associated with decreased survival. As many of the causes are potentially treatable, a complete diagnostic approach is indicated in these patients, except those who are terminally ill.
\end{abstract}

The gastrointestinal tract represents a specific target organ in the acquired immunodeficiency syndrome (AIDS): best estimates indicate that from 50 to $90 \%$ of all AIDS patients develop digestive manifestations during the course of their disease, ${ }^{12}$ consisting mainly of infections by opportunistic organisms or malignant neoplasm. ${ }^{3-6}$

Many of these abnormalities - for example infectious oesophagitis or gastroduodenal tumours - are potential sources of upper gastrointestinal haemorrhage. In addition, the risk of bleeding in AIDS patients may be further increased by severe thrombocytopenia, a condition that sometimes affects HIV infected individuals. ${ }^{78}$ In our experience, $8.9 \%$ of 608 drug addicts diagnosed to be HIV positive in 1985 presented with moderate to severe thrombocytopenia (platelet count $<110 \times 10^{9} / 1$ (unpublished data)).

Currently neither the incidence nor prevalence of acute gastrointestinal bleeding in AIDS patients is known, but it seems to be quite an uncommon manifestation. A number of clinical and necropsy studies have failed to describe a single case of acute upper gastrointestinal haemorrhage in more than 100 patients, ${ }^{29-11}$ but four cases of appreciable acute bleeding have recently been reported by Lane $e t a l^{12}$ in a series of 85 consecutive AIDS patients.

The purpose of the present study was twofold. Our first aim was to establish the cumulative incidence of acute upper gastrointestinal bleeding in a large series of patients with AIDS and the impact of this on the probability of survival. Secondly, we wished to determine the spectrum of gastrointestinal lesions responsible for acute upper digestive haemorrhage in these patients

\section{Patients and methods}

The initial study population comprised 461 consecutive patients with AIDS diagnosed at the L Sacco Hospital between June 1985 and March 1989. As this hospital is the referral centre for AIDS in the Milan district, these patients constituted more than $80 \%$ of the cases of AIDS diagnosed in this area during the study period. Eight subjects were excluded as they were foreign residents, thereby reducing the number to 453 patients.

AIDS was defined according to the Centres for Disease Control revised surveillance definition of $1985^{13}$ and the subsequent 1987 modification. ${ }^{14} \mathrm{~A}$ total of 378 patients were men and 75 were women: their mean age was 31.5 years (range 17 56). Risk factors for AIDS included a history of intravenous drug addiction in 307 patients $(67 \cdot 8 \%)$, homosexuality in 102 patients $(22 \cdot 5 \%)$, and blood transfusions or haemophilia in four $(0.9 \%)$; in 29 patients $(6.9 \%)$ the infection was thought to have been acquired heterosexually and $11(2 \cdot 4 \%)$ had unknown risk factors.

All patients had HIV positive serology by commercial enzyme immunoassay (Abbott Laboratories, Chicago, USA), and confirmed by western blotting. ${ }^{15}$ At diagnosis, complete biochemical tests and determination of $T$ lymphocyte subpopulations by direct immunofluorescence using monoclonal antibodies and flow cytometry ${ }^{16}$ were performed in all cases.

According to their platelet counts, patients were arbitrarily subdivided into three categories:

TABLE I Characteristics of patients at entry to the study

\begin{tabular}{lc}
\hline Total cohort & 453 \\
Sex ratio $(M / F)$ & $378 / 75$ \\
Age $($ mean $(\mathrm{SD})$ & $31 \cdot 5(8 \cdot 7)$ \\
Platelet count $\left(\times 10^{\%} / \mathrm{l}\right)($ no $(\%))$ & \\
$>110$ & $331(73)$ \\
$110-30$ & $104(23)$ \\
$<30$ & $18(4)$ \\
Absolute number of T4 lymphocytes $\left(\times 10^{\circ} / \mathrm{l}\right)($ no $(\%))$ & $62(13 \cdot 7)$ \\
$>200$ & $67(14 \cdot 8)$ \\
$200-100$ & $122(26 \cdot 9)$ \\
$100-50$ & $202(44 \cdot 6)$ \\
$<50$ &
\end{tabular}
16 October 1990

Gastroenterology and Saccous Diseases, F Parente

L Valsecchi

G Rizzardini

G Bianchi Porro

Department of Epidemiology, CNR, Milan, Italy
} 
severe thrombocytopenia $\left(<30\right.$ platelets $\left.\times 10^{\circ} / 1\right)$, moderate thrombocytopenia $(110-30$ platelets $x$ $\left.10^{9} / 1\right)$, and mild thrombocytopenia or platelet count within the normal range $\left(>110 \times 10^{9} / 1\right)$. Similarly, according to their absolute number of $\mathrm{T}$ helper lymphocytes (T4), patients were arbitrarily assigned to four subgroups: $\mathrm{T} 4$ depletion $\left(<50 \mathrm{~T} 4 \times 10^{6} / \mathrm{l}\right)$, moderate to severe $\mathrm{T} 4$ reduction $\left(50-100 \mathrm{~T} 4 \times 10^{6} / \mathrm{l}\right)$, moderate $\mathrm{T} 4$ decrease $\left(100-200 \mathrm{~T} 4 \times 10^{6} / \mathrm{l}\right)$, mild T4 decrease

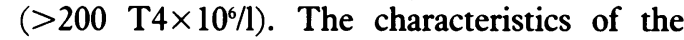
patients enrolled in the study are summarised in Table I.

The main clinical manifestations diagnostic of AIDS were: Pneumocystis carinii pneumonia in 152 patients, candida oesophagitis in 143 cases, Kaposi's sarcoma in 46 patients, and nonHodgkin's lymphomas in 37 cases.

Acute upper gastrointestinal bleeding was defined as one or more ascertained episodes of haematemesis or melena, or both, or the finding of fresh red blood in the nasogastric aspirate in a patient presenting with acute anaemia and doubtful history of melena or haematemesis, or both. An emergency oesophagogastroduodenoscopy was performed on all patients with evidence of bleeding, provided that individual conditions did not preclude the procedure. Endoscopy was sometimes followed by other laparotomy, as appropriate.

Patients who were terminally ill and whose conditions precluded endoscopy underwent necropsy to determine the potential sources of bleeding.

During follow up, patients were seen regularly in the clinic at approximately monthly intervals. For patients who died or were admitted to other hospitals, a complete hospital record, with particular reference to the cause of death or the occurrence of upper gastrointestinal bleeding immediately before or during admission, was obtained.

Survival analysis, according to the KaplanMeier method, ${ }^{17}$ was used to determine the cumulative time dependent probability of bleeding and survival. Statistical significance was calculated by $\log$ rank test. ${ }^{18}$ The strength of association between the main demographic, clinical, and laboratory variables and gastrointestinal bleeding was evaluated with odds ratios and their relative $\chi^{2} \cdot{ }^{19}$ The $95 \%$

Figure 1: Cumulative probability of acute upper gastrointestinal (GI) bleeding after the diagnosis of AIDS. investigations such as angiography or explorative

confidence intervals $(\mathrm{CI})$ of the odds ratios were determined as suggested by Miettinen. ${ }^{20}$

\section{Results}

Median follow up was 6 months (range: 1-42 months). During this period 15 patients suffered from one or more episodes of acute upper gastrointestinal bleeding. The cumulative probability of bleeding increased progressively over the first 14 months of follow up; bleeding rates were $3 \%$ at 6 months $(95 \% \mathrm{CI} 1 \cdot 4-4 \cdot 6), 5 \%$ at 12 months $(95 \% \mathrm{CI} 2 \cdot 3-7 \cdot 7)$, and $6 \%$ at 14 months (95\% CI 2·7-9.3) (Fig 1).

Acute upper gastrointestinal haemorrhage was significantly associated with the platelet count at the time of diagnosis. The frequency of bleeding increased progressively with the decrease in the number of platelets at diagnosis - at 15 months it was $2 \cdot 1 \%$ in patients with mild thrombocytopenia or whose platelet count fell within the normal range, $5.8 \%$ in those with moderate thrombocytopenia, and $11.1 \%$ in patients with severe thrombocytopenia $(p=0.05$, Table II). Conversely, there was no association between the absolute number of T4 lymphocytes at baseline, age, sex, or any of the particular risk factors for AIDS and acute bleeding.

Among the first clinical manifestations diagnostic of AIDS considered, only nonHodgkin's lymphoma was found to correlate with a significantly higher risk of acute haemorrhage $(\mathrm{p}<0.025)$. In these patients, $13.5 \%$ had gastrointestinal bleeding during follow up compared with only $2.4 \%$ of those without nonHodgkin's lymphoma (odds ratio $5 \cdot 6,95 \% \mathrm{CI}$ 1.8-17-7). Non-Hodgkin's lymphoma also remained a strong risk factor for bleeding after adjustment for the platelet count at baseline (Table III). Haemorrhage was associated with a significantly reduced patient survival. Estimated survival rates at 12 months were $8 \%$ in bleeding patients $v 64 \%$ in those who had not bled $(\mathrm{p}<0.001)$; in the latter group, estimated survival was as high as $24 \%$ at 27 months (Fig 2). The relative risk of death in bleeding patients was $5 \cdot 8$ times $(95 \%$ CI $3 \cdot 4-10 \cdot 3)$ that of the risk in patients who had had no episodes of bleeding.

TABLE II Acute upper gastrointestinal (GI) bleeding at 15 months according to some demographic and laboratory parameters at the time of diagnosis

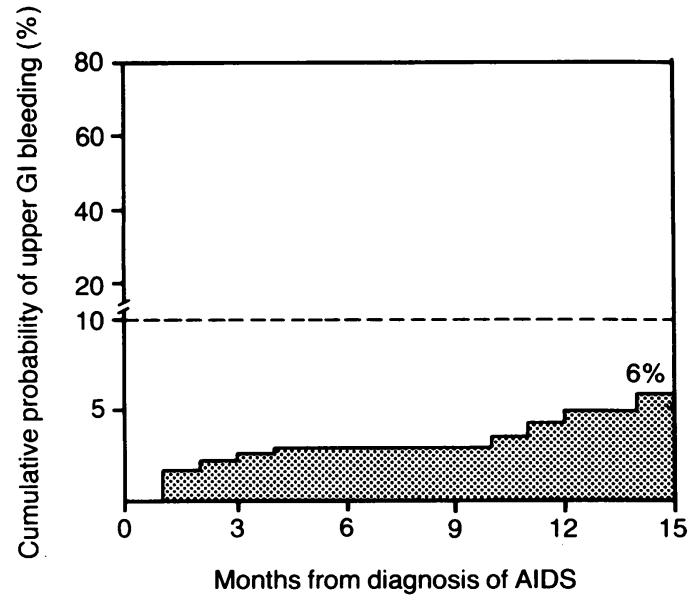

\begin{tabular}{|c|c|c|c|c|}
\hline Variable & $\begin{array}{l}\text { No of } \\
\text { Patients }\end{array}$ & $\begin{array}{l}\text { GI bleeding } \\
(\%)\end{array}$ & $\begin{array}{l}\text { Odds } \\
\text { ratio }\end{array}$ & $95 \% C I$ \\
\hline \multicolumn{5}{|l|}{ Age (years): } \\
\hline $17-25$ & 122 & $3(2 \cdot 5)$ & $1 \cdot 0$ & - \\
\hline $26-35$ & 154 & $6(3.9)$ & 1.6 & $0 \cdot 3-7 \cdot 8$ \\
\hline $36-45$ & 67 & $2(3 \cdot 1)$ & $1 \cdot 3$ & $0 \cdot 2-9 \cdot 8$ \\
\hline $46-66$ & 110 & $4(3.6)$ & 1.5 & $1 \cdot 5-8 \cdot 3$ \\
\hline \multicolumn{5}{|l|}{ Sex: } \\
\hline Male & 378 & $15(4 \cdot 0)$ & $1 \cdot 0$ & - \\
\hline Female & 75 & & 0 & - \\
\hline \multicolumn{5}{|l|}{ Risk factors: } \\
\hline IV drug abuse & 307 & $11(3 \cdot 5)$ & 1.0 & - \\
\hline Homosexuality & 102 & $3(2.9)$ & & - \\
\hline Other & 44 & $1(3 \cdot 0)$ & $0 \cdot 8$ & $0 \cdot 2-2 \cdot 9$ \\
\hline \multicolumn{5}{|l|}{ Platelets $\left(\times 10^{4} / 1\right)$ : } \\
\hline & 331 & $7(2 \cdot 1)$ & $1 \cdot 0$ & - \\
\hline $30-110$ & 104 & $6(5 \cdot 8)$ & & - \\
\hline$<30$ & 18 & $2(11 \cdot 1)$ & $3 \cdot 1$ & $1.0-9 \cdot 5$ \\
\hline \multicolumn{5}{|c|}{ T4 lymphocytes $\left(\times 10^{6} / 1\right):$} \\
\hline$>200$ & 62 & $2(3 \cdot 2)$ & $1 \cdot 0$ & - \\
\hline $200-100$ & 67 & $2(3.0)$ & 0.9 & $0 \cdot 1-7 \cdot 2$ \\
\hline $100-50$ & 122 & $2(1 \cdot 6)$ & $0 \cdot 5$ & $0 \cdot 1-4 \cdot 6$ \\
\hline$<50$ & 202 & $9(4 \cdot 4)$ & $1 \cdot 4$ & $0 \cdot 3-8 \cdot 2$ \\
\hline
\end{tabular}


TABLE III Acute upper gastrointestinal (GI) bleeding at 15 months in patients presenting with non-Hodgkin's lymphoma as the first manifestation of AIDS in relation to the platelet count at the time of diagnosis

\begin{tabular}{|c|c|c|c|c|c|c|}
\hline \multirow{2}{*}{$\begin{array}{l}\text { Acute GI } \\
\text { bleeding }\end{array}$} & \multicolumn{2}{|c|}{$\begin{array}{l}\text { Platelets }\left(\times 10^{4} / l\right) \\
>110\end{array}$} & \multicolumn{2}{|c|}{$<110$} & \multirow{2}{*}{$\begin{array}{l}\text { Odds } \\
\text { ratio* }\end{array}$} & \multirow[b]{2}{*}{$95 \% C I$} \\
\hline & Yes & No & Yes & No & & \\
\hline \multicolumn{7}{|c|}{ Non-Hodgkin's lymphoma: } \\
\hline $\begin{array}{l}\text { No } \\
\text { Yes }\end{array}$ & $\begin{array}{l}6 \\
1\end{array}$ & $\begin{array}{r}300 \\
24\end{array}$ & $\begin{array}{l}4 \\
4\end{array}$ & $\begin{array}{r}106 \\
8\end{array}$ & $\begin{array}{l}1 \cdot 0 \\
6 \cdot 3\end{array}$ & $1.9-20 \cdot 8+$ \\
\hline
\end{tabular}

An emergency oesophagogastroduodenoscopy was feasible in 10 patients. A potential cause of haemorrhage was identified in nine, but in the 10th patient the diagnosis was subsequently made at explorative laparotomy. Seven patients were found to be bleeding from AIDS related gastrointestinal lesions, and three were found to be bleeding from non-AIDS associated conditions (Table IV).

Necropsy examination of the five patients not submitted to any diagnostic procedures because of their severe clinical condition showed the following potential causes of haemorrhage respectively: erosive/haemorrhagic gastritis, multiple gastric and duodenal ulcers, duodenal Kaposi's sarcoma, cytomegalovirus oesophagitis, and oesophageal varices.

\section{Discussion}

Abnormalities of the gastrointestinal system are very common in patients with AIDS and are mainly superimposed opportunistic infections or opportunistic tumours. ${ }^{3-6}$ Their clinical expressions are protean, since any part of the gut from the oral cavity to the anus may be affected. ${ }^{21}$ While the frequency and the causes of the main symptoms, such as odynophagia/dysphagia and diarrhoea, have been extensively examined in large scale studies, ${ }^{22} 23$ the occurrence of gastrointestinal bleeding and its impact on the clinical outcome of AIDS patients has received only limited attention

In this study, which is to our knowledge the first specifically focusing on this problem, we have shown that acute upper gastrointestinal

Figure 2: Estimated survival rates in a cohort of 453 AIDS patients according to the occurrence of acute upper gastrointestinal bleeding.
TABLE IV Results of endoscopic procedures in patients with acute upper gastrointestinal bleeding

\begin{tabular}{lc}
\hline Lesion & $\begin{array}{l}\text { No of } \\
\text { patients }\end{array}$ \\
\hline Gastric and/or duodenal lymphoma & 3 \\
Candida oesophagitis (CO) & $1(+1)$ \\
HSV oesophagitis (+CO) & 1 \\
Cytomegalovirus oesophagitis & 1 \\
MAI complex duodenitis & 1 \\
Benign gastric ulcer & 1 \\
Duodenal ulcer & 1 \\
Oesophageal varices & 1 \\
Total & 10 \\
\hline
\end{tabular}

Oesophageal varices

Totat

HSV: Herpes simplex virus; MAI complex; Mycobacterium avium intracellulare complex.

$\star$ This diagnosis was subsequently made at explorative laparotomy as endoscopy showed only an extensive ulcerative duodenitis.

haemorrhage is an uncommon manifestation of AIDS, but its occurrence is associated with appreciably decreased patient survival. In the small subset of patients presenting with acute haemorrhage, median survival was only 62 days, in contrast with the large number of patients who never bled and whose clinical course was notably better, with a median survival of 549 days. Different factors may be responsible for this reduced survival. Firstly, bleeding may be linked directly to mortality. In six patients, death was an unequivocal consequence of massive haemorrhage; however, five of them were severely ill, which may have precluded their recovery from an event that they might have survived earlier in the course of the illness. Secondly, bleeding may reflect a more severe disease associated with a higher morbidity and mortality - for example AIDS related nonHodgkin's lymphoma. ${ }^{2+}$ In this respect, it is noteworthy that one third of the cases of acute bleeding were observed in patients whose presenting feature of AIDS was an extranodal nonHodgkin's lymphoma.

Among all the variables considered, other than the aforementioned first clinical manifestation of AIDS, only severe thrombocytopenia was an independent risk factor for bleeding. This may have important practical implications since it allows us to identify specific subgroups of patients with a higher risk of bleeding for whom a careful clinical and endoscopic surveillance is indicated.

With regard to the causes of acute upper gastrointestinal bleeding in this population, we have shown that it is just as likely to occur with AIDS related lesions as with non-specific pathologies. In approximately $60 \%$ of bleeding patients the cause was a direct consequence of HIV infection, whereas in the remainder, bleeding arose from sources not specifically associated with AIDS.

Among the AIDS related diseases, the most frequent cause of haemorrhage was gastric or duodenal non-Hodgkin's lymphoma, or both. This probably depends upon the high frequency of gastrointestinal localisation of these tumours and on their tendency to present with advanced lesions that can easily ulcerate and bleed. In our series, the upper gastrointestinal tract (namely the stomach or duodenum, or both) was involved in approximately $20 \%$ of patients with AIDS related extranodal non-Hodgkin's lymphoma. This incidence agrees with that reported by 
others, ${ }^{25}{ }^{26}$ but is probably underestimated as a result of insensitive antemortem diagnostic staging. In the experience of some authors, ${ }^{27}{ }^{28}$ up to $40 \%$ of patients with non-Hodgkin's lymphoma have gastrointestinal lesions at necropsy.

Despite the fact that gastrointestinal Kaposi's sarcoma lesions are believed to bleed frequently spontaneously or after biopsy - this event was rare in our population. In fact, in 19 patients with documented upper digestive involvement, only one case of haemorrhage from these lesions was observed.

Peptic ulcer disease represented the most frequent non-AIDS related cause of haemorrhage in patients undergoing emergency endoscopy. This may simply reflect the relatively high incidence of this condition in a population under 40 years of age, since no evidence exists that AIDS predisposes to peptic ulcer disease, but the extensive use of drugs, including non-steroidal anti-inflammatory agents, may enhance the risk of peptic ulcer bleeding in these patients.

Another important non-AIDS related cause of acute haemorrhage to be considered in these patients is portal hypertension. In our experience, oesophageal varices were responsible for bleeding in only $10 \%$ of the patients. Given the almost universal exposure of AIDS patients to hepatitis B virus infection ${ }^{29}$ and the frequency of abnormal hepatic histology in HIV carriers, ${ }^{3031}$ it is surprising that more cases of variceal bleeding have not been observed. It is our opinion that at least two factors could account for this apparent discrepancy. Firstly, cirrhosis of the liver is relatively unusual in patients with AIDS; in a necropsy study of ours, the frequency of cirrhosis was less than $10 \%$ in 131 consecutive patients and was related in most cases to hepatitis $B$ virus infection. ${ }^{32}$ This agrees with the reports of other authors ${ }^{3033}$ and is possibly due to an apparent protective effect of concurrent HIV infection upon the liver damage by hepatitis B virus. ${ }^{34}$ Secondly, AIDS patients with severe chronic liver damage may not live long enough to develop clinical manifestations of portal hypertension.

In summary, acute upper gastrointestinal bleeding rarely complicates the clinical course of AIDS, but its occurrence is associated with a decreased survival. When dealing with this problem, it is important that the physician should have an open mind with regard to the source of bleeding and should not consider this event as necessarily being due to the AIDS condition itself. As many of the causes of haemorrhage, including some AIDS related lesions, are potentially treatable, a complete diagnostic approach, which should include upper digestive endoscopy followed, where appropriate, by angiography or nuclear scintigraphy, is indicated in all patients except those who are terminally ill.

We would like to thank the medical and nursing staff in the Departments of Gastroenterology and Infectious Diseases of the $L$ Departments of Gastroenterology and Infectious Diseases of the $L$ possible.

This work was presented in part as an oral communication at the Annual General Meeting of the British Society of Gastro-
enterology, 27-29 September, 1989, Dublin and published in enterology, 27-29 September, 1989 ,
abstract form in Gut 1989; 30; A 1476.

1 Centres for Disease Control task force on Kaposi's sarcoma and opportunistic infections. Epidemiologic aspects of the current outbreak of Kaposi's sarcoma and opportunistic infections. N Engl ₹ Med 1982; 306: 248-52.

2 Malebranche $\mathrm{R}$, Guerin $\mathrm{JM}$, Laroche $\mathrm{AC}$, et al. Acquired immunodeficiency syndrome with severe gastrointestinal manifestations in Haiti. Lancet 1982; i: 873-7.

3 Gelb A, Miller S. AIDS and gastroenterology. Am $\mathcal{J}$ Gastroenterol 1986; 81: 619-22.

4 Rodgers VD, Kagnoff MF. Gastrointestinal manifestations of the acquired immunodeficiency syndrome. West $\mathcal{f}$ Med 1987; 146: 57-67.

5 Weller IVD. AIDS and the gut. Scand $\mathcal{F}$ Gastroenterol 1985; 20 (suppl 114): 77-89.

6 Bianchi Porro G, Parente F, Cernuschi M. The diagnosis of esophageal candidiasis in patients with AIDS. Is endoscopy always necessary? Am $\mathcal{F}$ Gastroenterol 1989; 84: 143-6.

7 Walsh C, Krigel R, Lennette E, Karpatkin S. Thrombocytopenia in homosexual patients. Ann Intern Med 1985; 103: $542-5$.

8 Ratner L. Human immunodeficiency virus-associated autoimmune thrombocytopenic purpura: a review. $A m \mathcal{F} \mathrm{Med}$ 1989; 86: 194-6.

9 Welch K, Finkbeiner W, Alpers CE, et al. Autopsy findings in the acquired immunodeficiency syndrome. $\mathcal{F} A M A 1984$ 252: 1152-8.

10 Urmacher C, Nielsen S. The histopathology of the acquired immunodeficiency syndrome. Pathology 1985; 20: 197-203.

11 Rene E, Marche C, Regnier B, et al. Manifestations digestives du syndrome d'immunodéficience acquise (SIDA); étude chez 26 patients. Gastroenterol Clin Biol 1985; 9: 327-32.

12 Lane GP, Lucas CR, Smallwood A. The gastrointestinal and hepatic manifestations of the acquired immunodeficiency hepatic manifestations of the acquired

13 Centres for Disease Control. Revision of the case definition of acquired immunodeficiency syndrome for national reporting-United States. MMWR 1985; 34: 373-5.

14 Centres for Disease Control. Revision of the CDC surveillance case definition for acquired immunodeficiency syndrome. MMWR 1987; 36 (suppl): 1-15S.

15 Carlson J, Bryant M, Hinrich S, et al. AIDS serology testing in low and high risk groups. $7 A M A 1985 ; 253 ; 3405-8$.

16 Stites D, Casavant C, McHugh T, et al. Flow cytometry analysis of lymphocyte phenotypes in AIDS using monoclonal anti-bodies and simultaneous dual immunofluorescence. Clin Immunol Immunopathol 1986; 38: 161-77.

17 Kaplan EL, Meier P. Non-parametric estimation from incom plete observations. F Am Stat Assoc 1958; 53: 457-81.

18 Peto R, Peto J. Asintottically efficient rank invariant test procedures. F $R$ Stat Soc A 1972; 135: 187-98.

19 Feinstein AR. Clinical epidemiology. The architecture of clinical research. Philadelphia: WB Saunders Company, 1985.

20 Miettinen OS. Estimability and estimation in case-referen studies. Am F Epidemiol 1976; 103: 226-35.

21 Bartlett JG, Layghon B, Quinn TC. Gastrointestinal complications of AIDS. In: AIDS. Aetiology, treatment, diagnosis and prevention. 2nd Edition. De Vita VT, Hellman S, Rosenberg SA, eds. Philadelphia: JB Lippincott, 1989: 227-44.

22 Connolly GM, Hawkins D, Harcourt-Webster JN, Parsons PA, Husain OAN, Gazzard BG. Oesophageal symptoms, their causes, treatment and prognosis in patients with the acquired immunodeficiency syndrome. Gut 1989; 30 : 1033-9.

23 René E, Marche C, Regnier B, et al. Intestinal infections in patients with acquired immunodeficiency syndrome. A prospective study in 132 patients. Dig Dis Sci 1989; 34: 773 80.

24 Di Carlo EF, Amberson JB, Metroka CE, Ballard P, Moore A, Mouradian JA. Malignant lymphomas and the acquired immunodeficiency syndrome. Arch Pathol Lab Med 1986; 110: 1012-6.

25 Ziegler JL, Beckstead JA, Volberding PA, et al. NonHodgkin's lymphoma in 90 homosexual men. Relationship Hodgkin's lymphoma in 90 homosexual men. Relationship to generalized lymphadenopathy and the acquired immun
deficiency syndrome. N Engl F Med 1984; 311: 565-70.

26 Levine AM, Gill PS, Muggia F. Malignancies in the acquired immunodeficiency syndrome. Curr Probl Cancer 1987; 11: 213-55.

27 Rosenberg SA, Diamond HD, Jaslowitz B, et al. Lympho sarcoma: a review of 1269 cases. Medicine $1961 ; 40$ : $31-42$.

28 Sherlock $P$. The gastrointestinal manifestations and complications of malignant lymphoma. Schweiz Med Wochenschr tons of malignant $1031-43$.

29 Lebovics E, Dworkin BM, Heier SK, Rosenthel WS. The hepatobiliary manifestations of human immunodeficiency hepatobiliary manifestations of human immunod
virus infection. Am $\mathcal{f}$ Gastroenterol 1988; 83: 1-7.

30 Schneiderman DV, Arenson DM, Cello JP, Margretter W Weber TE. Hepatic disease in patients with the acquired immune deficiency syndrome (AIDS). Hepatology 1987; 7 925-30.

31 Barrison IG, Price J, Logan R, Harris JRW, Pinching AJ Liver biopsy in human immunodeficiency virus antibody positive patients. In: AIDS gastroenterology and hepatology. Classen $M$, Dancygier $H$, eds. Grafelfing: Deneter Verlag, 1989: 61-2.

32 Caredda F, Vago L, Coppin P, Gaiera G, Pavani D, Parravicini C. Frequency of chronic active hepatitis $(\mathrm{CAH})$ or cirrhosis in patients with AIDS: an autoptical evaluation. Proceedings of the 6th International Conference on AIDS. San Francisco, of the 6th International Conference

33 Hubner K. Spectrum of liver pathology in AIDS. In: AIDS in gastroenterology and hepatology. Classen $\mathrm{M}$, Dancygier $\mathrm{H}$, eds. Grafelfing: Demeter Verlag, 1989: 53-6.

34 Rutsgi VK, Hoofnagle JH, Gerin JL, et al. Hepatitis B virus infection in the acquired immunodeficiency syndrome. $A n n$ Intern Med 1984; 101: 795-7. 